\title{
REHABILITATION AFTER SPINAL CORD INJURIES COMPLICATED BY PREVIOUS LESIONS
}

\author{
By Abraham Ohry, M.D. ${ }^{1}$ and Hans L. Frankel, F.R.C.P. ${ }^{2}$ \\ ${ }^{1}$ The Neurological Rehabilitation Department, Chaim Sheba Medical Centre, Tel \\ Hashomer 5262I, Israel. ${ }^{2}$ The National Spinal Injuries Centre, Stoke Mandeville \\ Hospital, Aylesbury, Bucks, U.K.
}

Summary. Since Sir Ludwig Guttmann introduced the comprehensive modern clinical approach to the rehabilitation of spinal cord injured patients much experience has been accumulated. Modern spinal cord injuries centres have opened throughout the world, treating mainly acute spinal cord injuries in young patients.

At Stoke Mandeville Hospital we have had the opportunity to treat several spinal patients who had suffered previous neurological or orthopaedic disorders. These complicated combinations affected the rehabilitation process and the presentations show clearly different aspects of the problem.

Key words: Spinal cord injury; Achondroplasia; Osteogenesis Imperfecta; Ankylosing spondylitis; Arthritis; Stroke hemiplegia; Cervical spondylitis.

\section{Introduction}

THE rehabilitation process of spinal cord injured patients (SCIP) consists of various components: medical (physical, neurological, orthopaedic, urological, etc.), psychological (acceptance of disability, coping with the handicap), vocational, sexological and sociological. The comprehensive team approach towards rehabilitation of the chronic and acutely disabled patients has proved effective even during the relatively short history of rehabilitation medicine.

Although most of the SCIP are young men who were injured while working, driving or during sport activities, we have had the opportunity to treat patients who had suffered from neurological or orthopaedic diseases prior to the accident.

This paper deals with the influence of this combination of previous diseases and recent SCI upon the rehabilitation process. To demonstrate the problem we shall briefly describe some typical cases.

\section{Case Reports}

I. J.V., a 30-year-old man suffering from osteogenesis imperfecta tarda. In February, I979 he was involved in a motorbike accident which resulted in complete paraplegia below $\mathrm{T}_{3}$, fractures of the left radius, right acetabulum and $\mathrm{C}_{4}$ spinous process. Since childhood the patient had been taught how to avoid injuries during sporting activities but he nevertheless had sustained many 'path slogical' fractures. After the SCI we were faced with special problems in this patient:

I. We had to select antibiotics which were not toxic to the inner ear, because he had suffered from some degree of deafness due to his disease. 
2. We had to prevent him from engaging in any sporting activities, such as 'push-ups' and other strenuous exercises, because of the danger of fractures. He now had severe osteoporosis due to his bone disease and due to the SCI.

3. Weakness, as he complained of being much weaker than before the injury.

4. Pulmonary problems due to the previous kyposcoliotic deformity and the recent respiratory muscle paralysis.

2. V.H., a 52-year-old man who had suffered from epilepsy and ankylosing spondylitis for many years. In I970, while walking to work (bread roundsman), the patient had a fit, fell to the floor and broke his cervical spine. He had had two similar attacks in the previous 2 months, from which no injuries occurred. He denied any 'aura', and the periods of unconsciousness lasted 4-5 minutes each time. When he woke up after the last fall he felt tired and noted froth on his mouth. Usually he had dizzy spells while sitting with a hyper-extended neck. From the age of I4-I 8 he suffered from Grand-Mal epilepsy, and for the last is years had presented signs of transient ischaemic attacks and migraine, probably due to his ankylosed cervical spine which caused vertebro-basilar insufficiency. His spinal injury was complete tetraplegia below $\mathrm{C} 6$, and although the rehabilitative process went well he was very incapacitated by the combination of spondylitis and tetraplegia, so much so that he could not even move his neck.

He now had two possible reasons for fainting, i.e. vertebrobasilar insufficiency and orthostatic hypotension. Unfortunately he died a few years later because of severe bronchopneumonia. Postmortem examination revealed gross spinal deformity due to ankylosing spondylitis, bedsores, enlarged liver and kidneys and a healed fracture of $\mathrm{C}_{5}, 6$.

3. J.A., a 75-year-old retired clerk, who 4 years before admission sustained a stroke with residual right hemiplegia. While walking on a pavement in October 1970 he tripped and fell, sustaining a hyperextension neck injury causing incomplete tetraplegia below $\mathrm{C}_{4}$. In 1957 he had undergone partial gastrectomy because of a bleeding duodenal ulcer and also suffered from chronic bronchitis.

Cervical X-ray showed osteoarthritic changes between $\mathrm{C}_{3-7}$ with almost complete degeneration of the disc spaces. Because of his previous pulmonary problem and the spinal injury he developed acute respiratory insufficiency, which was treated with artificial ventilation through a tracheostomy. He did not develop a 'stress ulcer' and he recovered slowly from all his initial complications.

The rehabilitation process went well, his walking ability improved despite his disability, age, chronic obstructive lung disease and arthritic pains in the cervical spine.

4. L.L., a 70-year-old shoe manufacturer suffered from right hip osteoarthritis, cervical and low back pains. In December I 979 he was schooling a horse which bolted, ran into a stable wall and hit the patient, causing mild head injury and tetraparesis below C6. Although much improvement of motor ability ensued a total hip replacement was carried out. The combined results of previous arthritic changes of the spinal column (limitation of movements and pains), and tetraparesis were devastating, complicated also by spastic and musculoskeletal pains. 
5. L.C., a 36-year-old man had suffered from ankylosing spondylitis since he was 18 years old. In 1972 he underwent THR, after which he could walk well. In October 1974 he was knocked down by a car, sustaining a fracture of C6-7 with incomplete tetraplegia below $\mathrm{C}_{7}$ and complete below T3. He developed a bleeding duodenal ulcer, which was treated conservatively. Severe limitation of neck movement, pain in shoulders and other joints slowed down his progress. He had also suffered from irido cyclitis and cataract. During the first year after discharge he developed renal failure and shortly afterwards died.

6. K.B., a 54-year-old man, who was found to be drunk, confused and suffering from facial injuries due to an unknown accident. On admission no neurological deficit was detected. The following day he was unable to move his extremities. At that time he was completely conscious. Cervical $\mathrm{X}$-rays showed marked angulation in extension at the $\mathrm{C}_{4}-5$ level, and the rest of the whole spine showed typical 'bamboo-spine' in a straight position. The fracture seemed stable. The patient hardly spoke English but the doctor understood that he had suffered from ankylosing spondylitis for many years. Because of free mobility of the neck the fracture may well have been old and the neurological signs due to 'contusion'. He was nursed flat with a collar and required bladder catheterisation. At that time he had good movement of his neck and of respiratory muscles. His right arm was slightly weak and the left arm had only minimal flexion with finger tips, and was flaccid. The leg power was reasonable with exaggerated tendon reflexes in both extremities and pyramidal signs in both lower limbs. Sensation was intact. Hospital radiologic investigation showed A.S. changes of the spine, severe arthritic changes in the shoulders and fracture-dislocation of $\mathrm{C}_{5}, 6$ firmly united with deformity. The sacro-iliac joints were fused with typical 'bamboo-spine' appearance. There was general deformity of the shoulders with clavicular and acromion destruction. He was transferred to Stoke Mandeville Hospital for further rehabilitation. The problem of old fractures compared with the new ones on the severely ankylosed spine was still in debate and it must be remembered that his neurological lesion was diagnosed 24 hours after admission. Treatment did not consist of skeletal traction as free neck movements might have caused the unstable fracture to damage the cord. Today he walks independently using only a walking stick and is able to stand, sit, transfer and perform all activities of daily living. He has no cardiovascular or sphincter troubles. During the rehabilitation process he had the following problems:

I. Difficulties in ADL and simple physical activities because of spastic tetraplegia and of rigidity of the spine.

2. Painful shoulders even during walking.

3. Rigid chest and weak respiratory muscles.

4. Non-active right shoulder and hand due to muscular atrophy.

7. J.S., a 30-year-old achondroplasic dwarf had suffered from incomplete tetraparesis since 1962 . She had tripped and fallen forwards the day before admission, causing quadriparesis. Radiographically, it was shown she suffered from osteoarthritis of the cervical spine and some degree of subluxation between the 2nd and 3 rd cervical vertebrae. She was treated by skull traction for several weeks and gradually improved. In April I96I she had had a further fall with the result that all the previous symptoms returned. 
At that time she was treated conservatively by immobilisation in P.O.P. collar and physiotherapy (Nov. I96I). Spinal fusion was performed with a bone graft taken from the tibia. Unfortunately, 2 weeks after the operation she tripped in the ward and broke that same tibia and now the leg was also immobilised in P.O.P. Upon discharge she was able to walk with special walking appliances. During the rehabilitation process she made considerable progress in walking and in independence but walking was hindered by spasticity due to incomplete $\mathrm{C}_{4}$ tetraparesis a painful sensation in the sacral area congenital physical deformity and overweight.

The 'phantom pain' phenomenon was manifested in this case as 'proctalgia' and root pain and proved intractable, leading to mental depression and agony. Over the years, the LBP worsened even during light weight bearing or after prolonged sitting, and this was only slightly improved by drug therapy. In November I 979 an ileal conduit bladder was performed for her miserable condition, inability to void and to manage her neuropathic bladder.

During the long follow-up period we had the impression that her neurological condition had progressively worsened, presumably as a result of spinal canal stenosis and repeated fractures. Today, she suffers from virtually complete spastic paraplegia. Over the years we were unable to find her a satisfactory wheelchair, but while she could walk a little this was less important. She is now confined to a wheelchair but her short arms cannot reach the driving wheel of any of the usual wheelchair models and she needs a powered chair which will suit her shape.

8. R.P., a 74-year-old man who suffered from cervical spondylitis. In I 965 he fell from a first floor window, causing incomplete tetraplegia below C6 and complete below T3. A few years before he had suffered from Petit-Mal seizures and hypothyroidism but no details were available. Following the injury he was unconscious for 2 hours and after coming round he complained of headaches and neck pains. The treatment consisted of conservative management for the S.C. lesion and phenobarbital therapy for the Petit-Mal fits. The rehabilitation outcome was poor because of his severe handicap, age, seizures and limitations of neck movement caused by spondylitic change.

\section{Discussion}

The rehabilitation process of SCI patients can be much more complicated if the subjects have previously suffered from various diseases, but the literature concerning this point is scarce. We have concentrated on several patients who had suffered from neurological or orthopaedic disorders prior to injury, such as osteogenesis imperfecta, ankylosing spondylitis, epilepsy and vertebrobasilar insufficiency, hemiplegia, chronic bronchitis, osteoarthritis, achondroplasia and cervical spondylitis. We have tried to emphasize the various rehabilitative problems which occurred during these patients' hospitalisation and how the combination of SCI and previous disorders affected the outcome.

The ankylosing spondylitis (A.S.) patient is prone to SCI even without evidence of trauma (Sorin et al., 1979). A.S. is a systemic inflammatory disease of the spinal column, resulting in progressive rigidity of the spine and thorax. The common fracture-dislocations are produced by a com- 
bination of the forces which produce fracture-dislocation in the A.S. or normal spine but the A.S. spine is more prone to injuries (Kattan, 1975). Due to its rigidity the spine breaks transversely, similar to fracture of long bones. Most of the fractures, even in minor trauma, occur at the level of $\mathrm{C}_{5}$,C6. There is no correlation between the degree of displacement and the degree of neurological damage. Guttmann (1966-7) described seven cases with clinical A.S. and traumatic SCI and assumed that the 'brittle' spine would give rise to frequent fractures even in minor accidents, such as slipping and falling to the ground. Most of the fractures were due to a retroflexion mechanism of hyperextension (Guttmann, I976). The explanation may be that the jarring effect of trauma on the ankylosed spine can result in acute damage to the vascular supply, either of the segmental vessels of the cord which are particularly numerous between $\mathrm{C}_{4}-\mathrm{C}_{7}$ or to the vertebral arteries and their descending branches.

One of our patients rarely suffered from vertebral basilar insufficiency and we found a similar (non traumatic) case recorded in the literature (Zeidler et al., I973). The recognition of the bony (cervical) damage can be difficult and any conservative treatment (reduction) should be carried out under X-ray control. Hewer (1966-7) described a case of upper thoracic SCI lesion in a patient with A.S. and Paget's disease.

The mechanism of the SCI was in doubt but it was apparent that the thoracic cord was stretched both by the hyphus and the tight dura, because no trauma was reported. The cervical spine may be damaged also in other rheumatic disorders like rheumatoid arthritis (Runawat et al., I979), senile spondylosis, rheumatic fever, lupus erythematosus etc. (Kattan, I975). In this paper we have described several elderly people with spondylosis or osteoarthritis. The effect of trauma on the cervical spine in elderly patients suffering from 'arthritis' can be devastating. They tend to have thoracic kyphosis and compensatory cervical lordosis. The spine is relatively rigid and fixed, the type of injury usually being 'hyper-extension'. The anterior longitudinal ligament ruptures together with the intervertebral disc. Rossier and Bors (1965), discussing the problem of the aged with SCI, indicated that the general condition of the patient and the extent (but not the level of injury), were the determining factors for length of survival. Previous cardiovascular problems, hypertension, pulmonary diseases, gastrointestinal (ulcers) or diabetes mellitus affected the outcome considerably.

Congenital anomalies or diseases may also predispose the patients to SCI. Dislocation of the atlas occurs readily in Morquio disease, Hurler syndrome, spondylo-epiphyseal dysphasia congenita or in neural arch defects such as spondylolithesis. We have demonstrated SCI in patients with achondroplasia (dwarfism) and one with osteogenesis imperfecta. Both conditions have a predisposition to neural trauma because of brittle bones and marked deformity. Hancock and Phillips (I965) mentioned two basic mechanisms as responsible for neurological dysfunction i.e. narrowing of the spinal canal (particularly in its AP diameter), and the development of severe augmentation at the dorso-lumbar junction. The narrowing is related to premature fusion of the pedicles to the laminae. The lumbar spine may be lordotic, or kyphotic, thus spinal straightening may be impaired. Constriction of the canal may be due to short vertebral bodies, hypertrophic discs, thickening pedicle or laminae, osteophyte formation, wedging of vertebra and disc protrusion-all of these pathological processes have been 
described. In this series only one was traumatic, and the results of treatment were disappointing (Galanski et al., I978; Lutter et al., I97I; Yang et al., 1977; Gulet et al., 1974). Finally patients with dwarfism also suffer from SCI.

We have tried to demonstrate clinically, with a brief review of the literature, how previous neurological and orthopaedic disorders affect the rehabilitation process after SCI.

\section{RÉSUMÉ}

Depuis que Sir Ludwig Guttmann a introduit une méthode clinique compréhensive et moderne de réadaptation des paraplégiques, une grande expérience a été acquise dans ce domaine. Des centres modernes pour le traitement des traumatismes médullaires ont été ouverts dans le monde entier; ils soignent surtout de jeunes traumatisés médullaires aigus.

A l'Hôpital de Stoke Mandeville, nous avons eu l'occasion de traiter plusieurs paraplégiques qui avaient auparavant souffert de troubles neurologiques ou orthopédiques. Ces combinaisons compliquées ont affecté le processus de réadaptation et les cas présentés indiquent clairement différents aspects du problème.

\section{ZUSAMMENFASSUNG}

Seitdem Sir Ludwig Guttmann eine moderne, umfassende, klinische Methode zur Rehabilitation der Paraplegiker eingeführt hat, wurde viel Erfahrung gesammelt. Moderne Anstalten für die Behandlung der Rückenmarkverletzungen sind in der ganzen Welt eröffnet worden; es werden dort vor allem akute, junge Rückenmarkverletzte behandelt.

In dem Stoke Mandeville Krankenhaus haben wir die Gelegenheit gehabt mehrere Paraplegiker die vorher unter neurologischen oder orthopädischen Beschwerden gelitten hatten zu pflegen. Diese komplizierten Kombinationen haben das Rehabilitationsverfahren beeinflusst und die vorgestellten Fälle zeigen klar verschiedene Aspekte des Problems.

\section{REFERENCES}

GALANSKI, M., HERMANN, R. \& KNOCKE, V. (1978). Neurological complications and myelographic features of achondroplasia. Neuroradiology, 17, 59-63.

Gulat, D. R. \& Rout, D. (1974). Atlantoaxial dislocation with quadriparesis in achondroplasia. F. Neurosurg., 40, 394-396.

GuttmanN, L. (1976). Tetraplegia in ankylosing spondylitis in Injuries of the spine and spinal cord, Vol. 26 in Handbook of Clinical Neurology. Ed. by P. J. Vinken \& C. W. Bruyn. North Holland Pub. Co., Amsterdam.

GutTMANN, L. (1966-7). Traumatic paraplegia and tetraplegia in ankylosing spondylitis. Paraplegia, 4, 188-201.

Hancock, O. D. \& Phillips, D. G. (1965). Spinal compression in Achondroplasia. Paraplegia, 3, 23-33.

HEWER, R. L. (1966-7). Spinal cord compression in a patient with ankylosing spondylitis and Paget's disease. Paraplegia, 4, 203-205.

KatTAN, K. B. (1975). Trauma and the Abnormal Spine. In Trauma and no trauma of the cervical spine. Ed. by K. R. Kattan. Charles C. Thomas, Pub., Springfield, Ill.

LutTer, L. D., Longstein, J. E., WinteR, R. B. \& LANGeR, L. C. (I977). Anatomy of the Achondroplastic lumbar canal. Clin. Orthop., 126, 139-142.

LUTTER, L. D. \& LANGER, L. O. (1977). Neurological symptoms in achondroplastic dwarfsurgical treatment. F. Bone F. Surg. (Amer.), 59(1), 87-92.

Rossier, A. \& BORS, E. (1965). Problems of the aged with spinal cord injuries. Paraplegia, 3, 34-45.

Ranawat, C., O’Leary, P., Pellici, P., Tsairis, P., Marchisello, P. \& Dorr, L. (1979). Cervical spine fusion in rheumatoid arthritis. F. Bone foint Surg., 6rA, I003-1010.

SORIN, S., Askari, A. \& Moskowitz, R. W. (1979). Atlantoaxial subluxation as a complication of early ankylosing spondylitis. Arthritis Rheum., 22, 273-276.

Yank, S. S., Cerbett, D. P., Brough, A. J., Heidelberger, A. \& Berstein, J. (1977). Upper cervical myelopathy in achondroplasia. Am. F. Clin. Pathol., 68, 66-72.

Zeidler, H., Wittenberg, A., Vegelsang, H. \& Weidner, A. (I973). Paraplegia and vertebral artery insufficiency caused by cervical spine involvement in chronic polyarthritis. Verh. Dtsch. Ges. Inn. Med., 79, 1414-1417. 